World Lumen Congress 2021 | May 26-30, 2021 | lasi, Romania

\title{
The Association between Social Integration, Coping Mechanisms and Anxiety in Patients with Non- Communicable Diseases
}

\author{
Rezarta LALO
}

https://doi.org/10.18662/wlc2021/33

How to cite: Lalo, R. (2021). The Association between Social Integration, Coping Mechanisms and Anxiety in Patients with Non-Communicable Diseases. In A. Sandu (vol. ed.), Lumen Proceedings: Vol. 17 World Lumen Congress 2021 (pp. 337-348). Iasi, Romania: LUMEN Publishing House. https://doi.org/10.18662/wlc2021/33 


\title{
The Association between Social Integration, Coping Mechanisms and Anxiety in Patients with Non- Communicable Diseases.
}

\author{
Rezarta LALO 1
}

\begin{abstract}
Recently, mental health issue and chronic physical condition are substantially linked and this comorbidity is likely to increase. Patient focusing in the self-care activities is an important component in the mechanism of coping with chronic disease with a significant impact on clinical and psychological outcomes. In this context, the current study is conducted to assess the impact of selfcare and social integration mechanisms on anxiety levels among patients with chronic noncommunicable diseases. This observational study of cross-sectional design was performed in the pathology service of Fier city hospital, in Albania during August-September 2020. To assess the level of anxiety, we used the scale of 7 items of General Anxiety Disorder (GAD-7) with a score of $\geq 10$ indicating GAD. Subscales of the Health Education Impact Questionnaire (heiQ) were used in order to evaluate social integration and self-care mechanism. The data were entered into the statistical program SPSS, version 23. The regression analysis is performed to examine the relationship between variables. The findings revealed that $56 \%$ of participants had $G A D, 47 \%$ of participants were unable to self-monitor the disease, while 89\% of them did not performe any type of physical activity. The scale of anxiety was significantly associated with variables of Selfmonitoring $(p=0.000<0.05 ; \mathrm{OR}=0.10)$ and Social integration $(p=0.000<0.05 ; O R=21.4)$.

These findings address the need to support people who struggle with chronic non-communicable diseases developing adaptive ways to deal with their chronic condition and improve their lifestyle for better overall health.
\end{abstract}

Keywords: Chronic diseases, anxiety disorder, self-monitoring, social integration, health directed activity, Fier city hospital.

\section{Introduction}

Worldwide, chronic non-communicable diseases are considered a major threat to people's health (Wang, Y., \& Wang, J., 2020). Referring to recent statistics of the World Health Organization (2016) (WHO), 80\% of

\footnotetext{
1 Doctor of Science, Lecturer in Faculty of Health, University of Vlora "Ismail Qemali", Albania. E-mail: rezarta lalo@yahoo.com
} 
the global burden of disease is due to chronic non-communicable diseases. Furthermore, developing countries of the European Region such as Albania are estimated to have the highest burden of NCDs (World Health Organization, 2018). The rate of morbidity and mortality attributed to NCDs in the Albanian population is estimated to be about $85 \%$ and 94\%,respectively (Burazeri, 2020). Although these statistics are really dramatic, they do not take into consideration the significance between chronic health conditions and their underlying risk factors. Recently, mental health issue and chronic physical condition are substantially linked and this comorbidity is likely to increase. Numerous studies have investigated that patients with major NCDs often have an affected psycho-emotional state (Farooq et al., 2019; Gerontoukouet al., 2015; World Health Organization, 2016). Under-estimated anxiety in primary care, but also within the hospital, is becoming more prevalent due to the increased older people and the exposure to chronic diseases (AlKhathami et al., 2017).

A review of international and albanian research has found that anxiety disorder among patients with chronic diseases remains underestimated and under-treated (Kamberi et al., 2016; Li et al., 2018). The nurse's focus on caring for chronic illness often can reduce their attention to identify the symptoms of anxiety in patients with chronic illness. Nurses should be aware to detect the early symptoms of anxiety in order to plan the proper management of the psychological well-being of chronic patients $(\mathrm{Li}$ et al., 2018). However, not only nurses should be equipped with knowledge about anxiety linked to chronic diseases, but also patients suffering from chronic diseases need to be educated to comprehend and self/manage the comorbid anxiety and chronic illness. Patient involvement in the self-care activities is an important component in the mechanism of coping with chronic disease with a significant impact on clinical and psychological outcomes (Pozza et al., 2020).

This identifies the need to assess the relationship between social integration, self-care mechanisms and anxiety in patients with chronic noncommunicable diseases in Fier City Hospital, Albania.

\section{Research Hypothesis}

This study is preceded by two main hypotheses:

2.1 Participants suffering from chronic non-communicable diseases exhibit symptoms of anxiety disorders

2.2 The level of self-management ability of chronic illness affects the anxiety level of the participants. 


\section{Research Methods}

This observational study of cross-sectional design was performed in the pathology service of Fier City Hospital, in Albania during AugustSeptember 2020. The sample included all patients hospitalized in this unit of the age more than 18 years old, of both sexes and treated for a chronic disease resulting in size of 250 participants. With the help of the ward nursing staff, patients with chronic diseases were identified, using the information of the medical cards, which were referred to the interviewers.

\subsection{Study Instruments.}

We used two validated instruments to obtain the data. To assess the level of anxiety, we used the scale of 7 items of General Anxiety Disorder (GAD-7) with a score of $\geq 10$ indicating GAD. According to the scoring criteria the level of anxiety is classified as Minimal Anxiety 0-4 points, Mild Anxiety 5-9, Moderate Anxiety 10-14 and Severe Anxiety 15-21 points (Spitzer, et al., 2006).

Subscales of the Health Education Impact Questionnaire (heiQ) were utilized to measure participants 'self-management capacities and skills (Osborne, et al., 2007). The HeiQ is a validated tool designed to evaluate the impact of educational interventions on patient's health, composed of 8 subscales, which measure self-management capacities. In this study, we used three subscales as independent questionnaires related to the intended outcomes: Health directed activities, Self-monitoring and insight, Social integration and support. Each subscale contains 4-6 items, the answers to which are marked on a 4-point Likert scale using the endpoints "strongly disagree/strongly agree". The total score is divided by the number of items. A higher score shows greater ability to self-manage the disease.

\subsubsection{Construct Definitions of the Health Education Impact Questionnaire.}

Health Directed Behavior: It is related to a lifestyle change and healthful behaviors including prevention, diet, and exercise.

Self-Monitoring and Insight: This scale is used to measure the individual's ability to monitor physical and emotional well-being in order to benefit insight and appropriate capacity to self-management.

Social Integration and Support: This construct implies social engagement to interact with others by sharing health-related experiences (Osborne, et al., 2007). 


\subsection{Data Statistical Analysis}

The data were entered into the statistical program SPSS, version 23. The regression analysis is performed to examine the relationship between variables considering $\mathrm{p}<0.05$ as a statistically significant value.

\section{Ethics approval}

The study is approved by the Ethics Council of the University "Ismail Qemali" of Vlora, Prot. No. 102/2, on 24/06/2020 and Directorate of Regional Hospital of Fier district Prot. No. 1685/1, on 29/07/2020 before the study commences.

The questionnaires were anonymous and data privacy was ensured by respecting ethical principles of Declaration of Helsinki. An informed oral consent was provided by all participants.

\section{Results}

The mean age of participants was $64.3 \pm 7.88$ years (range $45-85$ ). The majority of them were female $(54 \%, \mathrm{n}=135)$. A total of $8 \mathrm{NCD}$ was presented among participants, with diabetes mellitus $(n=131)$, heart diseases $(\mathrm{n}=69)$, hypertension $(\mathrm{n}=26)$, chronic lung diseases $(\mathrm{n}=6)$, osteoarthritis $(n=6)$, bronchial asthma $(n=5)$, anemia $(n=4)$, chronic kidney disease $(n=3)$. The results related to GAD 7-ItemScale presented in table no. 1 found that $50 \%$ of participants were feeling nervous and anxious, $40 \%$ of them have been trouble relaxing and $37 \%$ were not able to control the feeling of worry.

Table 1. The evaluation of anxiety level of participants based on GAD-7 items Scale

\begin{tabular}{lcccc}
\hline $\begin{array}{l}\text { Over the last } 2 \text { weeks, } \\
\text { how often have you been } \\
\text { bothered by the following } \\
\text { problems? }\end{array}$ & $\begin{array}{c}\text { Not At } \\
\text { All }\end{array}$ & $\begin{array}{c}\text { Several } \\
\text { Days }\end{array}$ & $\begin{array}{c}\text { Over Half the } \\
\text { Days }\end{array}$ & $\begin{array}{c}\text { Nearly } \\
\text { Every Day }\end{array}$ \\
\hline $\begin{array}{l}\text { Feeling nervous, anxious, or } \\
\text { on edge }\end{array}$ & $1(0.4 \%)$ & $\begin{array}{c}124 \\
(49.6 \%)\end{array}$ & $109(43.6 \%)$ & $16(6.4 \%)$ \\
$\begin{array}{l}\text { Not being able to stop or } \\
\text { control worrying }\end{array}$ & $23(9.2 \%)$ & $\begin{array}{c}134 \\
(53.6 \%)\end{array}$ & $84(33.6 \%)$ & $9(3.6 \%)$ \\
$\begin{array}{l}\text { Worrying too much about } \\
\text { different things }\end{array}$ & $4(1.6 \%)$ & $120(48 \%)$ & $120(48 \%)$ & $6(2.4 \%)$ \\
$\begin{array}{l}\text { Trouble relaxing } \\
\text { Being so restless that it's }\end{array}$ & $20(8 \%)$ & $\begin{array}{c}116 \\
(46.4 \%) \\
124\end{array}$ & $110(44 \%)$ & $4(1.6 \%)$ \\
\end{tabular}


hard to sit still

Becoming easily annoyed or irritable

Feeling afraid as if something awful might happen

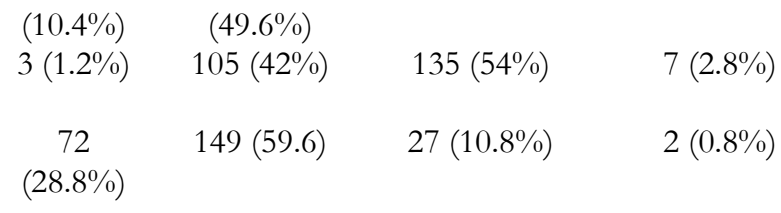

Mean GAD-7 score is 9.5 \pm 3.5 . The majority of patients (131 patients or $52 \%$ ) had moderate anxiety, $36 \%$ mild anxiety and only $3.2 \%$ had severe anxiety (Figure 1).

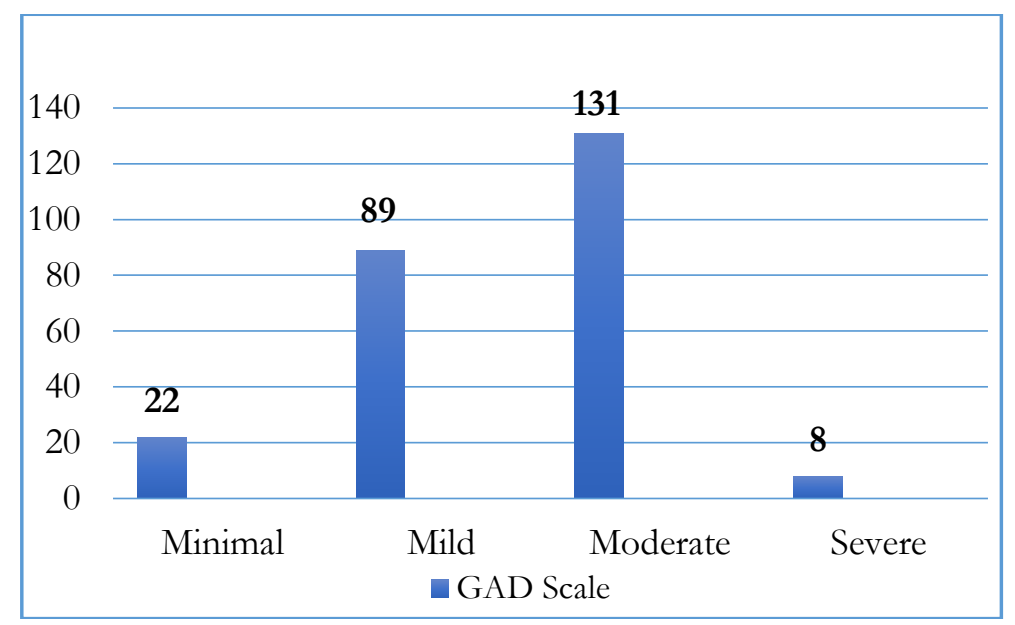

Figure 1. GAD-7 Score Symptom Range

Regarding to healthy-directed activity, the results presented in table no. 2 showed that $89 \%$ of participants didn't do any type of physical activity, 88\% didn 't make walking in the daily routine.

Table 2. Evaluation of health-related activities of participants

\begin{tabular}{|c|c|c|c|c|c|}
\hline Health-directed activity & $\begin{array}{l}\text { Strongly } \\
\text { disagree }\end{array}$ & Disagree & Agree & $\begin{array}{c}\text { Strongly } \\
\text { agree }\end{array}$ & Total \\
\hline On most days of the week, I do & 204 & 13 & 32 & 1 & 250 \\
\hline $\begin{array}{l}\text { at least one activity to improve } \\
\text { my health (e.g. walking, } \\
\text { relaxation, exercise). }\end{array}$ & $81.6 \%$ & $5.2 \%$ & $12.8 \%$ & $0.4 \%$ & $100 \%$ \\
\hline I do at least one type of & 204 & 19 & 26 & 1 & 250 \\
\hline $\begin{array}{l}\text { physical activity every day for at } \\
\text { least } 30 \text { min (e.g.walking, } \\
\text { gardening, housework, golf, } \\
\text { bowls, dancing, swimming). }\end{array}$ & $81.6 \%$ & $7.6 \%$ & $10.4 \%$ & $0.4 \%$ & $100 \%$ \\
\hline
\end{tabular}


On most days of the week, I set aside time for healthy activities (e.g. walking etc.)

I walk for exercise, for at least 15 min per day, most days of the week

$\begin{array}{ccccc}204 & 16 & 29 & 1 & 250 \\ 81.6 \% & 6.4 \% & 11.6 \% & 0.4 \% & 100 \%\end{array}$

$\begin{array}{ccccc}204 & 16 & 29 & 1 & 250 \\ 81.6 \% & 6.4 \% & 11.6 \% & 0.4 \% & 100 \%\end{array}$

The findings related to respondents' capacity of self-monitoring and insight presented in table no. 3 indicated that $59 \%$ of them didn 't know what factors can cause their health problems, 59\% didn't have a clear comprehension how to take control health problems, while $55 \%$ didn`t monitor their health to do what is necessary to keep as healthy as possible.

Table 3. Evaluation of capacity of self-monitoring and insight of respondents

\begin{tabular}{lccccc}
\hline \multicolumn{1}{c}{ Self-monitoring and insight } & $\begin{array}{c}\text { Strongly } \\
\text { disagree }\end{array}$ & Disagree & Agree & $\begin{array}{c}\text { Strongly } \\
\text { agree }\end{array}$ & Total \\
\hline As well as seeing my doctor, I & 117 & 21 & 110 & 2 & 250 \\
regularly monitor changes in my & $46.8 \%$ & $8.4 \%$ & $44 \%$ & $0.8 \%$ & $100 \%$ \\
health. & & & & & 250 \\
I know what things can trigger my & 117 & 31 & 100 & 2 & 250 \\
health problems and to aggravate & $46.8 \%$ & $12.4 \%$ & $40 \%$ & $0.8 \%$ & $100 \%$ \\
them. & & & & & 2 \\
I have a very good understanding of & 117 & 27 & 104 & 2 & 250 \\
when and why I am supposed to & $46.8 \%$ & $10.8 \%$ & $41.6 \%$ & $0.8 \%$ & $100 \%$ \\
take my medication. & & & & & 250 \\
When I have health problems I have & 117 & 30 & 101 & 2 & $100 \%$ \\
a clear understanding what to do to & $46.8 \%$ & $12 \%$ & $40.4 \%$ & $0.8 \%$ & \\
$\begin{array}{l}\text { control them. } \\
\text { I carefully watch my health and do }\end{array}$ & 117 & 22 & 109 & 2 & 250 \\
what is necessary to keep as healthy & $46.8 \%$ & $8.8 \%$ & $43.6 \%$ & $0.8 \%$ & $100 \%$ \\
$\begin{array}{l}\text { as possible. } \\
\text { With my health in mind, I have }\end{array}$ & 117 & 29 & 102 & 2 & 250 \\
realistic expectations of what I can & $46.8 \%$ & $11.6 \%$ & $40.8 \%$ & $0.8 \%$ & $100 \%$ \\
and cannot do. & & & & & \\
\hline
\end{tabular}

According to the results presented in table no. 4 related to the construct "social integration and support", $56 \%$ of participants didn 't have many friends to help them cope with their chronic illness, 57\% say that when they feel ill, their family and careers didn`t understand what they are going through. 
Table 4. Evaluation of the construct of social integration and support among participants

\begin{tabular}{lccccc}
\hline \multicolumn{1}{c}{ Social Integration and Support } & $\begin{array}{c}\text { Strongly } \\
\text { disagree }\end{array}$ & Disagree & Agree & $\begin{array}{c}\text { Strongly } \\
\text { agree }\end{array}$ & Total \\
\hline If I need help, I have plenty of & 133 & 9 & 105 & 3 & 250 \\
people I can rely on & $53.2 \%$ & $3.6 \%$ & $42 \%$ & $1.2 \%$ & $100 \%$ \\
I have enough friends who help me & 133 & 7 & 108 & 2 & 250 \\
cope with my health problems & $53.2 \%$ & $2.8 \%$ & $43.2 \%$ & $0.8 \%$ & $100 \%$ \\
When I feel ill, my family and carers & 133 & 9 & 106 & 2 & 250 \\
really understand what I am going & $53.2 \%$ & $3.6 \%$ & $42.4 \%$ & $0.8 \%$ & $100 \%$ \\
through & & & & & \\
Overall, I feel well looked after by & 133 & 9 & 106 & 2 & 250 \\
friends and family & $53.2 \%$ & $3.6 \%$ & $42.4 \%$ & $0.8 \%$ & $100 \%$ \\
I get enough chances to talk about & 133 & 10 & 105 & 2 & 250 \\
my health problems with people who & $53.2 \%$ & $4 \%$ & $42 \%$ & $0.8 \%$ & $100 \%$ \\
understand me. & & & & & \\
\hline
\end{tabular}

The study found that the scale of anxiety was statistically associated with variables of Self-monitoring $(\mathrm{p}=0.000<0.05$; $\mathrm{OR}=0.10)$ and Social integration $(p=0.000<0.05 ; \quad O R=21.4)$, similarly with another study (Uhlenbusch et al., 2019). The relationship between Social Support, Coping Mechanisms and Anxiety is presented in table no. 5. The results showed that patients with low levels of social integration and low ability to selfmonitor their illness were more prone to moderate and high levels of anxiety.

Table 5. Relationship Between Social Integration \&Support, Coping Mechanisms and Anxiety

\begin{tabular}{|c|c|c|c|c|c|c|c|c|}
\hline \multirow[b]{2}{*}{$\begin{array}{c}\text { HeiQ } \\
\text { Constructs }\end{array}$} & \multirow{2}{*}{$\begin{array}{c}\text { Score } \\
\text { Constru } \\
\text { ct Range }\end{array}$} & \multicolumn{4}{|c|}{ GAD-7 Score Symptom Range } & \multirow[b]{2}{*}{$\begin{array}{c}\text { Tota } \\
1\end{array}$} & \multirow[b]{2}{*}{$\mathrm{p}$} & \multirow[b]{2}{*}{ OR } \\
\hline & & $\begin{array}{l}\text { Minim } \\
\text { al } \\
0-4 \\
\text { points }\end{array}$ & $\begin{array}{c}\text { Mild } \\
5-9 \\
\text { point } \\
\text { s }\end{array}$ & $\begin{array}{c}\text { Moderat } \\
\text { e } \\
10-14 \\
\text { points }\end{array}$ & $\begin{array}{l}\text { Sever } \\
\mathrm{e} \\
15-21 \\
\text { points }\end{array}$ & & & \\
\hline \multirow{3}{*}{$\begin{array}{c}\text { Self- } \\
\text { monitoringan } \\
\text { d insight }\end{array}$} & Low & 2 & 37 & 76 & 2 & 117 & \multirow{3}{*}{$\begin{array}{c}0.00 \\
0\end{array}$} & \multirow{3}{*}{$\begin{array}{l}0.10 \\
(0.01- \\
0.84)\end{array}$} \\
\hline & Mean & 1 & 9 & 19 & 4 & 33 & & \\
\hline & High & 19 & 43 & 36 & 2 & 100 & & \\
\hline \multirow{3}{*}{$\begin{array}{l}\text { Health- } \\
\text { directed } \\
\text { activity }\end{array}$} & Low & 19 & 70 & 108 & 7 & 204 & \multirow{3}{*}{$\begin{array}{c}0.61 \\
4\end{array}$} & -------- \\
\hline & Mean & 1 & 7 & 14 & 0 & 22 & & \\
\hline & High & 2 & 12 & 9 & 1 & 24 & & \\
\hline Social & Low & 1 & 43 & 84 & 5 & 133 & 0.00 & 21.4 \\
\hline
\end{tabular}




$\begin{array}{ccccccccr}\text { Integration } & \text { Mean } & 21 & 45 & 45 & 3 & 114 & 0 & (2.64- \\ \text { and Support } & \text { High } & 0 & 1 & 2 & 0 & 3 & & 180.00)\end{array}$

\section{Discussion}

All over the world, including our country Albania, previous research has found that anxiety disorders have a significant prevalence in patients with chronic non-communicable diseases (Clarke \& Currie, 2009) although statistics vary nationally and geographically (World Health Organization, 2017; Li et al., 2018). This fact was also reflected in our study, which showed that about $56 \%$ of participants manifested symptoms of anxiety, which confirms the first hypothesis raised about the prevalence of anxiety. In different studies it has been observed that the prevalence varies, even within the same country (Alharithy et al., 2019). Thus, in a study carried out among patients hospitalized in the Regional Hospital of Vlora in Albania, it was found that psychological disorders were more pronounced in those suffering from chronic diseases, mainly female but with slightly lower values compared to our study (Kamberi et al., 2016). This inconstancy can be explained by the impact of various factors, as using different instruments which measure anxiety. Sample size, cultural factors or the prevalence of several chronic diseases have their influence too (Alharithy et al., 2019). Our results also indicated that patients with low levels of social integration and low ability to self-monitor their illness were more prone to moderate and high levels of anxiety, which indicates the urgent need to implement educational programs for their effective management. This finding supports the second hypothesis of this study. These findings are similar to many studies that have shown that physical inactivity, lack of support and selfmanagement have been considered as potential risk factors in NCD burden (Budreviciute et al., 2020; Peters et al., 2019). Regarding the relationship between the construct "health-oriented activities" and the "level of anxiety" of patients with chronic diseases, no statistically significant association was observed. However, the results showed that despite the fact that patients thought that the cause of their disease could be a diet with fats and a sedentary life, they still in a high percentage did not engage in physical activity, which identifies the need for their awareness about changing lifestyle. Another study performed by Laursen in 2017, indicated that HeiQ constructs served as useful components in increasing the ability to manage chronic disease and reduce the negative emotional effects after participating in an education program for patients with diabetes. Future research will help 
us to understand exactly the effectiveness of these programs in improving the rate of chronic diseases in Albania.

\section{Strength and Limitations}

This study has several advantages: Information on the diagnoses of chronic diseases is obtained from clinical records, avoiding self-reporting which results in higher reliability of sample selection. Also, our study is the first study to estimate the influence of social integration and self-care mechanisms on the level of anxiety in patients with non-communicable diseases. However, there have been a number of limitations that need to be mentioned.

First, it is the reliability in self-reporting about variables such as anxiety, as clinical tests by mental health specialists could obtain a proper diagnosis of mood disorders. However, GAD-7 has been shown to be a useful and reliable means of screening anxiety (Kroenke et al., 2007; Löwe et al., 2008; Spitzer et al., 2006).

Second, the observational type of this research complicates the interpretation of any causes and effect relationship.

Third, in this study we have used only three subscales of the HeiQ. Future studies using all constructs of HeiQ will provide a complete profile on the effectiveness of patient's education programs.

Finally, the lack of other studies of this kind in Albania limits the comparison with the database of national scientific research in this field.

\section{Conclusions}

The findings of present study provided a significant evidence related to the comorbidity of anxiety disorder and NCD's among patients in Fier City Hospital, since such data in Albania are limited.

More than half of the patients had insufficiency in relation to the ability to self-monitor the chronic disease and low level of integration and social support, variables which had an impact on the deterioration of the psychological condition of the patients.

Implementing and involving patients with chronic diseases in educational programs, applying HeiQ as a tool designed to measure their effectiveness, will be a new approach for health professionals staffs to better understand self-management skills acquired, coping mechanisms and psycho-social disturbances as well as behavioral strategies for choosing a healthy lifestyle. 


\section{The relevance of the study}

This study provides important insights about the current status of health behavioral practices, anxiety risk in some diagnoses of noncommunicable diseases and follow-up programs to reduce it. The passive role of albanian practitioners in increasing the skills of patients to selfmanage their chronic conditions highlights the importance of implementing self-management in the routine healthcare to keep the international standard of patient-centred healthcare. Looking after and providing mental health services to patients with chronic diseases should be a priority for health policymakers in Albania.

\section{References}

Alharithy, M. K., Abdalgader, O. R., Alobaylan, M. M., Alsugair, Z. O., \&Alswat, K. A. (2019). Anxiety prevalence in type 2 diabetes patients in Taif Saudi Arabia. Saudi Journal for Health Sciences, 8(2), 88-92. https://www.saudijhealthsci.org/text.asp?2019/8/2/88/261538

AlKhathami, A. D., Alamin, M. A., Alqahtani, A. M., Alsaeed, W. Y., AlKhathami, M. A., \& Al-Dhafeeri, A. H. (2017). Depression and anxiety among hypertensive and diabetic primary health care patients. Could patients' perception of their diseases control be used as a screening tool?. Saudi medical journal, 38(6), 621-628. https://doi.org/10.15537/smj.2017.6.17941A

Budreviciute, A., Damiati, S., Sabir, D. K., Onder, K., Schuller-Goetzburg, P., Plakys, G., Katileviciute, A., Khoja, S., \& Kodzius, R. (2020). Management and Prevention Strategies for Non-communicable Diseases (NCDs) and Their Risk Factors. Frontiers in public health, 8 . https://doi.org/10.3389/fpubh.2020.574111

Burazeri, G. (2020). Burden of non-communicable diseases and behavioral risk factors in Albania. European Journal of Public Health, 30(5). https://doi.org/10.1093/eurpub/ckaa165.848

Clarke, D. M., \& Currie, K. C. (2009). Depression, anxiety and their relationship with chronic diseases: a review of the epidemiology, risk and treatment evidence. The Medical journal of Australia, 190(S7), 54-60. https://doi.org/10.5694/j.1326-5377.2009.tb02471.x

Farooq, S., Khan, T., Zaheer, S., \& Shafique, K. (2019). Prevalence of anxiety and depressive symptoms and their association with multimorbidity and demographic factors: a community-based, cross-sectional survey in Karachi, Pakistan. BMJ open, 9(11). https://doi.org/10.1136/bmjopen$\underline{2019-029315}$

Gerontoukou, E.-I., Michaelidoy, S., Rekleiti, M., Saridi, M., \& Souliotis, K. (2015). Investigation of anxiety and depression in patients with chronic diseases. Health Psychology Research, 3(2). https://doi.org/10.4081/hpr.2015.2123 
Kamberi, F., Nelaj, D., Ndreu, V., Sinaj, E., \& Kamberi L. (2016) Is The Tendency of Depression in Hospitalized Patients Related With Chronic Diseases? An Exploratory Study. Proceeding of the 21st International Conference Association of Psychology \& Psychiatry for Adults \& Children. Greece. https://doi.org/10.13140/RG.2.1.3293.3520

Kroenke, K., Spitzer, R. L., Williams, J. B., Monahan, P. O., \& Löwe, B. (2007). Anxiety disorders in primary care: prevalence, impairment, comorbidity, and detection. Annals of internal medicine, 146(5), 317-325. https://doi.org/10.7326/0003-4819-146-5-200703060-00004

Laursen, D. H., Christensen, K. B., Christensen, U., \& Frølich, A. (2017). Assessment of short and long-term outcomes of diabetes patient education using the health education impact questionnaire (HeiQ). BMC research notes, 10(1). https://doi.org/10.1186/s13104-017-2536-6

Li, H., Ge, S., Greene, B., \& Dunbar-Jacob, J. (2018). Depression in the context of chronic diseases in the United States and China. International journal of nursing sciences, 6(1), 117-122. https://doi.org/10.1016/j.ijnss.2018.11.007

Löwe, B., Decker, O., Müller, S., Brähler, E., Schellberg, D., Herzog, W., \& Herzberg, P. Y. (2008). Validation and standardization of the Generalized Anxiety Disorder Screener (GAD-7) in the general population. Medical care, 46(3), 266-274. https://doi.org/10.1097/MLR.0b013e318160d093

Osborne, R. H., Elsworth, G. R., \& Whitfield, K. (2007). The Health Education Impact Questionnaire (heiQ): an outcomes and evaluation measure for patient education and self-management interventions for people with chronic conditions. Patient education and counseling, 66(2), 192-201. https://doi.org/10.1016/j.pec.2006.12.002

Peters, R., Ee, N., Peters, J., Beckett, N., Booth, A., Rockwood, K., \& Anstey, K. J. (2019). Common risk factors for major noncommunicable disease, a systematic overview of reviews and commentary: the implied potential for targeted risk reduction. Therapeutic advances in chronic disease, 10. https://doi.org/10.1177/2040622319880392

Pozza, A., Osborne, R. H., Elsworth, G. R., Gualtieri, G., Ferretti, F., \&Coluccia, A. (2020). Evaluation of the Health Education Impact Questionnaire (heiQ), a Self-Management Skill Assessment Tool, in Italian Chronic Patients. Psychology research and behavior management, 13, 459-471. https://doi.org/10.2147/PRBM.S245063

Spitzer, R. L., Kroenke, K., Williams, J. B., \& Löwe, B. (2006). A brief measure for assessing generalized anxiety disorder: the GAD-7. Archives of internal medicine, 166(10), 1092-1097. https://doi.org/10.1001/archinte.166.10.1092

Uhlenbusch, N., Löwe, B., Härter, M., Schramm, C., Weiler-Normann, C., \& Depping, M. K. (2019). Depression and anxiety in patients with different rare chronic diseases: A cross-sectional study. PloS one, 14(2). https://doi.org/10.1371/journal.pone.0211343 
Wang, Y., \& Wang, J. (2020). Modelling and prediction of global noncommunicable diseases. BMC public health, 20(1). https://doi.org/10.1186/s12889-020-08890-4

World Health Organization. (2016). Action plan for the prevention and control of noncommunicable diseases in the WHO European Region. Copenhagen: WHO Regional Office for Europe. World Health Organization. https://www.euro.who.int/en/about-us/governance/regional-committeefor-europe/past-sessions/66th-session/documentation/workingdocuments/eurrc6611-action-plan-for-the-prevention-and-control-ofnoncommunicable-diseases-in-the-who-european-region

World Health Organization. (2017). Depression and other common mental disorders: global bealth estimates. World Health Organization http://apps.who.int/iris/bitstream/handle/10665/254610/WHO-MSDMER-2017.2 eng.pdf;jsessionid $=$ AF90F1082645C497062D5FD9650888CE?sequence $=1$

World Health Organization. (2018). Noncommunicable diseases country profiles 2018. World Health Organization. https://apps.who.int/iris/handle/10665/274512 